\title{
ESTUDOS
}

\section{A promoção automática em questão: argumentos, implicaçôes e possibilidades}

Jefferson Mainardes

Discute a promoção

automática no Brasil, a partir: a)

da análise de diferentes

argumentos em trabalhos

publicados e b) de experiências pioneiras e atuais (Ciclo Básico de Alfabetização). Aponta-se possibilidades, implicações e condições necessárias para o êxito desta medida no sistema educacional brasileiro.
Palavras-Chave: promoção automática; ciclo básico de alfabetização; política educacional.

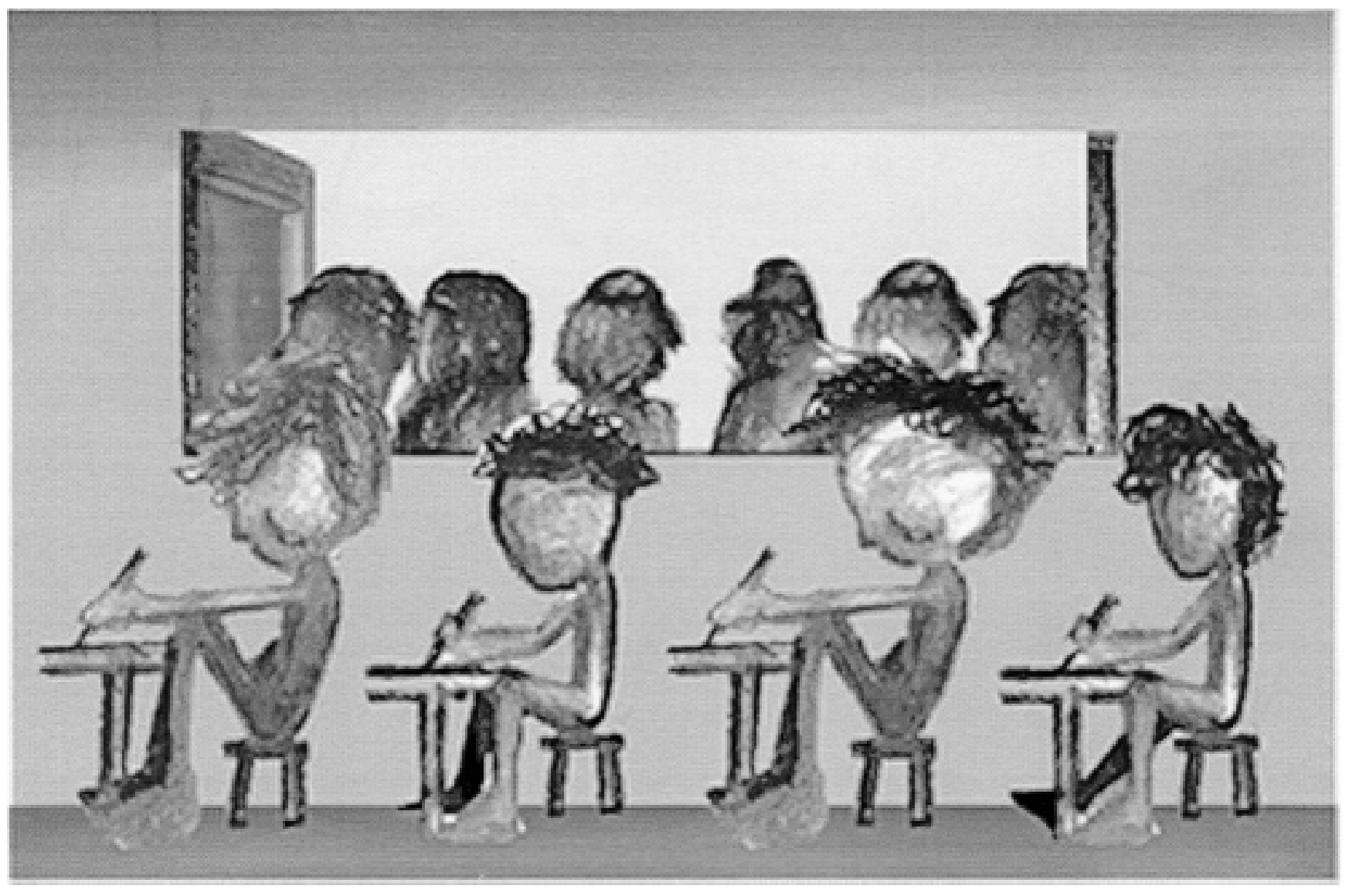




\section{Introdução}

Este texto foi apresentado em 1994, na 17 ${ }^{\text {a }}$ Reunião Anual da Associação Nacional de Pós-Graduação e Pesquisa em Educação (Anped), realizada em Caxambu-MG, alcançando, na época, razoável repercussão e entendido como tema atual e relevante. De lá para cá, entretanto, novas perspectivas e propostas educacionais configuraram-se na educação brasileira. Surgiram, em diversos estados e municípios, propostas de "aceleração de aprendizagem", "organização escolar por ciclos", projetos de adequação/correção "idade-série", "classes aceleradas", etc, todas elas voltadas à diminuição e/ou eliminação do histórico fenômeno da reprovação que há tanto tempo assombra os educadores e pesquisadores brasileiros. Também os Parâmetros Curriculares Nacionais adotam a organização da escolaridade em ciclos. Mesmo considerando tais "mudanças" nas práticas e nos discursos, o autor não fez qualquer tentativa de revisar ou adequar o texto inicial, deixando intactas as reflexões e propostas daquele momento histórico.

A proposta da eliminação da reprovação (promoção automática), apesar de ser implantada no Brasil com maior freqüência nos sistemas de ensino a partir da década de 80, com a implantação do Ciclo Básico de Alfabetização (CBA) em vários estados (São Paulo, Minas Gerais, Paraná, Goiás e outros), não é recente. Já no final da década de 50 , existiam discussões a respeito de sua validade (Almeida Júnior, 1957; Leite, 1959) motivadas, principalmente, pela discussão internacional em torno da necessidade da implantação de tal medida nos países do Terceiro Mundo. A Unesco, na primeira Reunião Internacional de Ministros de Educação, realizada em Genebra, em 1961, recomendava esta modalidade escolar para países do terceiro mundo com problemas de cobertura na área rural (Rojas Rubio, 1992, p. 79). No Brasil, em 1921, na Conferência Interestadual de Ensino Primário, Oscar Thompson, quando diretor-geral do ensino, recomendava a "promoção em massa". Sampaio Dória, em 1918, aconselhava expressamente o seguinte: "promover do primeiro para o segundo período todos os alunos que tivessem tido o benefício de um ano escolar, só podendo os atrasados repetir o ano, se não houver candidatos aos luga- res que ficariam ocupados. Semelhante medida equivale não permitir que se negue matrícula aos novos candidatos, só porque vadios ou anormais, teriam de repetir o ano" (Almeida Júnior, 1957).

Nas décadas de 60 e 70, as redes estaduais de ensino de São Paulo (19601972), Santa Catarina (1970-1984) e Rio de Janeiro (1979-1984) implantaram propostas com promoção automática. Apesar destas diferentes experiências levadas a efeito no Brasil, a promoção automática é ainda uma questão polêmica e o seu impacto para a elevação das taxas de aprovação e melhoria da qualidade do ensino são controversos.

O reduzido número de dados sistematizados das redes que a implantaram ou ainda a mantêm, não permite conclusões muito amplas sobre sua validade $\mathrm{e}$ eficácia. Da mesma forma, a discussão em torno dessa problemática tem sido rara no Brasil, indicando a necessidade de ser tomada como objeto de pesquisas. Em outros países, existem várias pesquisas que abordam a problemática, destacando-se os estudos de Shiefelbeim e Simmons (1978), Tedesco (1981), Muñoz e Lavin (1988), Rojas Rubio (1992).

Na primeira parte deste trabalho, buscando contextualizar a discussão, analisase alguns dados referentes ao acesso e permanência do aluno na escola brasileira; na segunda parte apresenta-se uma revisão de diferentes argumentos sobre a promoção automática, em trabalhos publicados no Brasil. Na terceira parte, buscou-se estabelecer um breve balanço sobre as principais experiências brasileiras que empregaram a medida da promoção automática e dados sobre o CBA de São Paulo, Minas Gerais e Paraná, enquanto propostas que eliminam a reprovação nas séries iniciais. Finaliza-se apresentando algumas conclusões, implicações e suas possibilidades para a transformação da escola, das práticas avaliativas, universalização do ensino e melhoria da qualidade da educação.

\section{Acesso e permanência: alguns dados}

A análise de estatísticas educacionais mostra que houve um avanço significativo, nas últimas décadas, em relação ao acesso à escola. Na década de 30 , ape- 
nas cerca de $60 \%$ das crianças brasileiras tinham acesso à escola primária (Freitas, apud Ribeiro, 1993). Atualmente, 95\% delas matriculam-se na $1 \underline{a}$ série do 10 grau e $69 \%$ o fazem com 7 anos de idade ou menos.

Em 1988, para uma população de 7 a 14 anos, de 26 milhões e 500 mil; $21 \mathrm{mi}-$ Ihões e 500 mil estavam na escola de 1 o grau (81,2\%); 636 mil $(2,4 \%)$ estavam na pré-escola; 2 milhões $(7,5 \%)$ estavam evadidos e um milhão e 400 mil $(5,3 \%)$ estavam sem acesso à escola de $10 \mathrm{grau}$. Dos $5,3 \%$ sem acesso à escola de 10 grau, $4,2 \%$ (ou seja $80 \%$ ) encontravam-se na região rural do Nordeste. Assim, a falta de escola "deixou de ser um problema nacional para ser um problema de uma região miserável do Nordeste rural" (Ribeiro, 1993, p. 65).

As taxas de escolarização da população de 7 a 14 anos de idade apresentaram uma evolução significativa nas últimas décadas: em 1950, foi de $36,2 \%$, em 1960 , de $45,4 \%$, em 1970 , de $67,1 \%$, em 1980 , de $80,4 \%$, atingindo $86,9 \%$ em 1990 (Brasil, 1994, p. 110). Apesar dos índices crescentes, cerca de 3,5 milhões de crianças brasileiras permanecem ainda sem oportunidade de acesso ao ensino fundamental. Apenas dois quintos concluem as quatro séries iniciais e menos de um quarto as concluem sem repetência. Os efeitos acumulados dessa baixa produtividade expressam-se na reduzida escolaridade média da população (os dados do PNAD/87 mostram que somente $25 \%$ da população com 10 anos de idade ou mais chegam a completar no máximo um ano de estudos) e no grande contingente de adolescentes e adultos subescolarizados.

Se a expansão da oferta garantiu o acesso da maioria da população, o problema da permanência do aluno na escola e sua promoção não foi ainda resolvido. No Brasil, os índices de reprovação e de evasão escolar aumentaram desde a década de 80. Entre 1979 e 1985, o índice de evasão cresceu $24 \%$ e o índice de repetência 14\%. Constata-se, com tais índices, a inércia estrutural do sistema e a perpetuação dos elevados índices de fracasso escolar, quase que inalterados desde a década de 40.

Para Fletcher e Ribeiro (1987), a repetência é o mais grave e o mais geral de todos os problemas da educação brasileira, uma vez que: a) limita o acesso e contribui para o atraso do ingresso de alu- nos novos; b) pode contribuir para a evasão; c) aumenta a despesa do ensino; d) a educação formal sempre tenta transmitir um saber padronizado.

O fenômeno da distorção idade/série aponta para a precariedade de um sistema que acolhe e retém alunos além da idade escolar obrigatória, mas não oportuniza a promoção de elevado número de alunos. Para exemplificá-lo, tomou-se dados estatísticos do Estado do Paraná. Aos 14 anos de idade, os alunos desta faixa etária deveriam estar freqüentando a $8 \underline{a}$ série do 1 o grau, no entanto, em 1990, tinha-se a seguinte distribuição: entre uma população escolarizável de 211.192; 42,4\% estavam fora da escola; $0,5 \%$ estavam na 1 a série do 1 o grau; $12,8 \%$ estavam na 5 a série; $12,5 \%$ estavam na 6 a série; $11,9 \%$ estavam na $7 \underline{\text { a }}$ série e apenas $12,2 \%$ estavam na $8^{\underline{a}}$ série (Paraná, 1992, p. 53).

Outra possibilidade de investigar a eficácia do sistema de ensino é a análise da progressão dos alunos no ensino de 1 응 grau numa série histórica, verificando-se o número de alunos ingressantes e o de concluintes. Este tipo de análise permite uma certa aproximação do número de alunos que conseguem realizar o 10 grau em oito anos e, conseqüentemente, indicadores do nível de desempenho da escola. Em relação à progressão dos alunos do ensino de 10 grau, constata-se no Estado do Paraná, na última década, os seguintes resultados: dos 393.044 alunos que ingressaram na 1 a série em 1980, apenas $142.681(36,3 \%)$ concluíram a 4a série em 1983 e $58.421(14,8 \%)$ concluíram a $8^{a}$ série. Isso significa que, para cada 100 alunos que ingressaram na $1 \underline{\text { a }}$ série em 1980 , apenas 15 concluíram o 1 으 grau em 1987 (em oito anos). Ainda que as taxas de conclusão estejam crescendo $(16,81 \%$ para os alunos que ingressaram em 1981 e $17,44 \%$ para os que ingressaram em 1982), não deixam de evidenciar a ineficácia do sistema. A respeito do "fluxo de alunos", convém destacar que existem formas mais sofisticadas e mais eficazes para analisar essa questão, tal como propõe Ribeiro (1993) e Silva e Davis (1993), que analisam dados educacionais corrigidos pelas Pesquisas Nacionais por Amostra de Domicílios (PNADs) do Instituto Brasileiro de Geografia e Estatística (IBGE). A tabela a seguir apresenta o fluxo da matrícula do ensino de 10 grau no Estado do Paraná: 
Tabela 1 - Fluxo da matrícula do ensino de 10 grau Total do Estado do Paraná - 1977-1992

\begin{tabular}{|c|c|c|c|c|c|c|c|c|}
\multicolumn{3}{c}{$\begin{array}{c}\text { 1a série } \\
\text { (ingressantes) }\end{array}$} & \multicolumn{3}{c}{$\begin{array}{c}\text { 4a série } \\
\text { (aprovados) }\end{array}$} \\
\hline Ano & Matrícula & $\%$ & Ano & Matrícula & $\%$ & Ano & Matrícula & $\%$ \\
\hline 1977 & 447.365 & 100 & 1980 & 149.148 & 33,33 & 1984 & 52.775 & 11,79 \\
1978 & 439.376 & 100 & 1981 & 151.541 & 34,49 & 1985 & 56.559 & 12,88 \\
1979 & 408.767 & 100 & 1982 & 144.312 & 35,30 & 1986 & 57.743 & 14,12 \\
1980 & 393.044 & 100 & 1983 & 142.681 & 36,30 & 1987 & 58.421 & 14,86 \\
1981 & 372.358 & 100 & 1984 & 143.797 & 36,81 & 1988 & 62.606 & 16,81 \\
1982 & 377.633 & 100 & 1985 & 148.730 & 39,38 & 1989 & 65.820 & 17,42 \\
1983 & 383.499 & 100 & 1986 & 154.629 & 40,32 & 1990 & 72.197 & 18,82 \\
1984 & 388.197 & 100 & 1987 & 158.368 & 40,70 & 1991 & 76.166 & 19,62 \\
1985 & 369.207 & 100 & 1988 & 161.186 & 43,65 & 1992 & 84.153 & 22,79 \\
1986 & 365.616 & 100 & 1989 & 163.388 & 44,68 & - & - & - \\
1987 & 352.682 & 100 & 1990 & 167.514 & 47,49 & - & - & - \\
1988 & 352.649 & 100 & 1991 & 176.358 & 50,01 & - & - & - \\
1989 & 337.643 & 100 & 1992 & 182.594 & 54,07 & - & - & - \\
1990 & 347.094 & 100 & - & - & - & - & - & - \\
\hline
\end{tabular}

Fonte: Paraná. SEED/Fundepar. Boletim Informativo. 1990.

Paraná Fundepar. Movimento Escolar. 1981-1992.

A proposta de eliminação da reprovação, diante dos dados estatísticos, aparece como medida correta e viável para a universalização do ensino básico (descongestiona o sistema, abrindo vagas), para a elevação progressiva do rendimento escolar do ensino de 10 grau e mudança do caráter seletivo da escola.

\section{Alguns argumentos}

Almeida Júnior (1957, p. 8) em um artigo intitulado "Repetência ou promoção automática?", relata sua participação na Conferência Regional sobre Educação Gratuita e Obrigatória, promovida pela Unesco em 1956, em Lima-Peru, quando se discutiu um estudo de técnicos da Unesco sobre reprovações na escola primária de 4 países da América Latina (EI Salvador, México, Colômbia e Brasil). O autor comenta que a reprovação acarreta problemas como a evasão escolar, desperdício de recursos financeiros e a estagnação de alunos reprovados nas séries iniciais do curso primário, que "enveIhecem e ocupam o lugar destinado às novas gerações".

O autor rejeita a simples promoção em massa, a expulsão dos reprovados e a promoção por idade cronológica (solução da Inglaterra) como uma medida isolada, mostrando-se favorável à adoção da solução inglesa, porém imitando-a "em toda a sua estratégia e não apenas no desfecho", o que exigiria a tomada de providências tais como: aperfeiçoamento de professores; modificação da então vigente concepção de ensino primário; revisão dos programas e critérios de promoção; cumprimento da escolaridade obrigatória, com a convocação de todos os alunos de oito anos para a escola; melhorar a formação do professor nos cursos regulares. Considera o autor: "aproveitemos a lição alheia; não porém, tão-somente a da sua página final, a da promoção automática" (idem, p. 11 e 14), lembrando as condições de eficiência que precisariam ser criadas para a implantá-la.

Leite (1959), no artigo "Promoção automática e adequação do currículo ao desenvolvimento do aluno", considera que a criança reprovada tem três alternativas: considerar-se incapaz, considerar as exigências da escola absurdas ou desnecessárias, ou continuar admitindo que é capaz (apesar de todas as provas em contrário). Para o autor, nenhuma delas é satisfatória. A escola, segundo ele, aceita a reprovação pelas seguintes razões: a) a escola foi, tradicionalmente, uma instituição seletiva; b) admite-se que as classes devem ser homogêneas e c) acredita-se que o castigo e o prêmio sejam formas de provocar ou acelerar a aprendizagem. Para transformar a escola numa instituição 
eficiente, o autor propõe a organização de um currículo adequado ao desenvolvimento do aluno e a instituição da promoção automática (por idade cronológica). A partir dessa promoção seria possível pensar o currículo adequado às diferentes idades. Segundo ele, a instituição da promoção automática causaria uma transformação radical na escola:

- as classes apresentariam um maior desnível entre os alunos;

- os vários grupos que se formariam dentro de uma classe deveriam receber diferentes tarefas e, por isso, a aprendizagem se tornaria mais ativa e a função do professor estaria restrita a "auxiliar a aprendizagem que cada grupo ou subgrupo está a realizar" (Almeida Júnior, 1957, p. 29);

- a aprendizagem ativa envolve uma participação muito grande dos alunos. Neste tipo de aprendizagem, "os alunos menos que no ensino tradicional, a aprendizagem é mais lenta, mas o que se aprende permanece por tempo maior e é mais utilizável pelo aprendiz".

As medidas necessárias para a instituição da promoção automática e adequação do currículo ao desenvolvimento do aluno apresentadas eram:

a) criação de critérios objetivos, capazes de estimular um aperfeiçoamento dos trabalhos didáticos;

b) os professores deveriam modificar os métodos de ensino, substituindo a preleção ou aula pela organização e orientação de tarefas para os grupos e subgrupos de cada classe.

Para o autor, o programa da promoção automática estaria destinado a completo fracasso se os executores (professores, diretores, inspetores) não "estiverem convencidos da sua necessidade, assim como de suas limitações".

Em publicação recente, Silva e Davis (1993, p. 7) apresentam importantes reflexões acerca da promoção automática. Para as autoras, a polêmica em torno da promoção automática vem se acumulando, mas acaba por escamotear a realidade, impedindo o exame da questão central: "a incapacidade da escola brasileira de abandonar suas práticas centenárias e virar do avesso sua organização interna". Analisando resultados do Ciclo Básico implantado em São Paulo (1984) e Minas Gerais (1985), apontaram que o "remanejamento" de alunos, em busca de classes homogêneas, apesar de ser pouco estimulado pelas Secretarias de Educação dos respectivos estados, continuava sendo empregado e o trabalho diversificado em sala de aula não foi adotado.

As autoras defendem:

a) garantir em todas as séries do ensino fundamental o sistema de promoção automática: a escola precisa enfrentar o problema de reorganizar-se para constituir uma prática diferente. Se a escola não for colocada frente a esta situação, os professores das séries onde não existe a promoção automática mantêm suas antigas práticas e recompõem os níveis de seletividade que existiam antes. Assim, é preciso quebrar o círculo vicioso, tomando consciência de que o regime seriado precisa ser repensado. A promoção automática, ainda que necessária, não é suficiente para garantir a melhoria da qualidade do ensino e a escola só será capaz de repensar sua organização quando conseguir livrar-se do fantasma da reprovação. A alternativa proposta pelas autoras aos estados que nunca implantaram a promoção automática é a de introduzi-la inicialmente num grupo de escolas, na forma de um projeto piloto. Para os estados que já possuem promoção automática nas séries iniciais, recomendam a expansão para as demais séries o mais rapidamente possível;

b) organizar as classes apenas e exclusivamente por faixa etária, buscando destruir a noção de que é possível e eficiente formar classes homogêneas. As escolas devem perceber as vantagens dos grupos heterogêneos, introduzindo como critério básico da organização das classes a faixa etária dos alunos;

c) desestimular os remanejamentos;

d) instrumentalizar o professor para trabalhar com grupos heterogêneos;

e) estabelecer um sistema de acompanhamento contínuo do processo de implantação da inovação educacional;

f) criar sistemáticas de avaliação e controle que garantam patamares mínimos de desempenho. Tais avaliações devem resultar em diretrizes para reformular o trabalho da equipe escolar;

g) informar a sociedade civil (com dados confiáveis), visando dar continuidade às mudanças propostas.

Arelaro (1992), referindo-se ao Ciclo Básico de São Paulo, argumenta que esta proposta "desestrutura" positivamente a seriação tradicional e colabora para a 
construção de uma escola mais democrática. Duran (1990, p. 19), também referindo-se ao CBA de São Paulo, destaca que a reprovação nas séries iniciais (e em todo o ensino fundamental) não se resolve com a promoção automática, "ainda que o fato de se conseguir que as crianças permaneçam um ano mais na escola, sem reprovação, por si só, seja positivo".

\section{Experiências de promoção automática no Brasil}

Foram diversas as experiências já desenvolvidas ou em desenvolvimento com a promoção automática. Para este estudo selecionou-se experiências que foram ou estão sendo desenvolvidas em redes estaduais de ensino, visto atingirem uma abrangência maior.

\section{Organização em níveis - São Paulo (1968-1972)}

Em 1968, a Secretaria de Estado da Educação de São Paulo implantou a chamada reforma do ensino primário (Ato $\mathrm{n}$ - 306, de 19/11/68) que compreendia, em suas alterações principais, a modificação na seriação do ensino, eliminando a reprovação do aluno entre a $1 \underline{\underline{a}}$ e $2 \underline{ }$ a séries (nível I) e entre as 3르 e 4aㅡ séries (nível II). A promoção de um nível para outro dar-seia mediante o alcance dos mínimos fixados nos programas de ensino.

Segundo Ambrosetti (1989, p. 29), a reforma foi recebida com desconfiança pelo magistério, e à medida que as mudanças se efetivaram, a desconfiança se transformou em resistência e rejeição. $A$ eliminação da retenção ao final do primeiro ano letivo "provocou um acúmulo de classes de 20 ano nas escolas, já que a retenção se transferiu para o final do nível e a concentração de alunos com maiores dificuldades de aprendizagem nas chamadas classes lentas ou $2^{\circ}$ ano de 'mentira', sem que fosse dada aos professores que assumiam as classes orientação necessária para o trabalho com esse alunos".

Segundo Arelaro (1988, p. 265), apesar do Ato 306/68 nunca ter sido expressamente revogado, em 1972, a organização em níveis deixou de existir. A autora aponta as razões: o grupo favorável à medida "cai" no início de maio de 1970, sob a suspeita de "subversivos" e a alegação de que a Lei no 5.692/71 dispunha sobre a organização do currículo em séries anuais. A proposta da promoção automática ressurgiu no sistema estadual paulista, com a implantação do Ciclo Básico, em 1984.

\section{Sistema de avanços progressivos - Santa Catarina (1970-1984)}

O Sistema de Avanços Progressivos (SAP) foi implantado na 1 a e $5^{\underline{a}}$ séries, a partir de 1970 na rede estadual de ensino de Santa Catarina, atingindo gradativamente todo o sistema de ensino de 1 응 grau do estado. Tal implantação foi considerada como demagógica, visando solucionar problemas "estatísticos" e não os educacionais (Arelaro, 1988, p. 242). Segundo Auras (1988, p. 165), o SAP foi imposto sem as reais condições de propiciar seu funcionamento (salas de aula com menor número de alunos, material didático, maior tempo de permanência do aluno na escola, melhores condições de trabaIho), servindo para "garantir a deterioração do ensino em nossas escolas públicas. Os alunos eram promovidos automaticamente para as séries seguintes. Deste modo, alunos praticamente não-alfabetizados concluíam a 1grau".

As principais pesquisas que avaliaram - SAP constataram que a reprovação apenas diminuiu (em 1966, a taxa média de reprovação nas 8 séries foi de $32,44 \%$ e em 1979 foi de $12,89 \%$ ) e a evasão ficou ainda mais alarmante (em 1966, a taxa média das 8 séries foi de $4,82 \%$ e em 1979 foi de $9,65 \%$ ) (Dutra et al., 1984). Sena e Medeiros (1984) apontam que muitos professores demonstravam desconhecer as características e abrangências do referido sistema de avaliação. Em outubro de 1984, durante a realização do Congresso Estadual de Educação - 1985-1988, foi quase unânime a exigência do fim daquele sistema.

\section{Bloco Único - Rio de Janeiro (1979-1984)}

No Rio de Janeiro, de 1979 a 1984, adotou-se o Bloco Único na rede estadual, instituindo-se a passagem automática da 1 a para a $2^{\mathrm{a}}$ série, como estratégia para assegurar uma maior permanência da criança na escola e permitir maior tempo para que o aluno pudesse completar sua alfabetização. No Rio de Janeiro também não foram 
tomadas outras providências de formação de pessoal, melhoria das condições de trabalho e capacitação de professores. Foi extinto em 1984, ainda que as classes de alfabetização e as de 1 a série tenham, na prática, formado um "bloco", instalando-se a prática de dois anos para a $1 \underline{\text { a }}$ série e, portanto, de nove anos para o $1^{\circ} \mathrm{grau}$.

A partir de 1993, o Bloco Único foi novamente implantado, abolindo a seriação entre as classes de alfabetização e a 4a série do 10 grau. A implantação dessa medida não agradou a maioria dos professores. Segundo uma pesquisa realizada para o jornal $O$ Globo, pelo Programa Interuniversitário de Pesquisas e Demandas Sociais (Prodeman), 54\% dos professores manifestaram-se contrários, $22 \%$ a favor com reservas e $14 \%$ francamente favoráveis ("Da temeridade...", 1993).

Estas experiências mostram que a promoção automática não foi acompanhada das condições necessárias para seu êxito, agravando o problema ao invés de solucioná-lo. Os pontos comuns nessas experiências foram a ausência de discussão prévia com os professores, insuficientes estratégias de capacitação docente, o não oferecimento das condições necessárias. Em relação ao trabalho pedagógico, percebe-se, em todas elas, dificuldades dos professores com classes muito heterogêneas, indicando que este aspecto é fundamental, devendo ser levado em conta na implantação de propostas com promoção automática. A resistência dos professores ocorreu nas três experiências, apontando que o "reformismo autoritário", sem negociação com os professores e demais profissionais da educação constitui-se um entrave para o êxito das mesmas. Os resultados negativos e as falhas ocorridas nestes projetos citados parecem não ter sido considerados nas experiências atuais. A implantação da proposta do CBA em vários estados tem repetido faIhas e equívocos.

\section{Ciclo Básico de Alfabetização (CBA): uma combinação da promoção automática com outras estratégias}

Com as eleições para os governos estaduais em 1982, ocorreu a vitória das oposições em dez estados brasileiros, entre eles São Paulo, Paraná, Minas Gerais, Goiás e Rio de Janeiro. Esse fato produziu mudanças na política educacional desses estados, apontando para uma nova visão do papel da escola pública. Nesse contexto, grupos políticos e educadores progressistas assumiram importantes cargos nas instâncias mediadoras ou nelas passam a interferir de forma mais intensa.

Comprometidos com o discurso da "mudança" na Educação, atendimento às aspirações da sociedade e democratização do ensino, esses governos tentam implantar medidas inovadoras na escola pública. Foi no bojo do compromisso com tais mudanças que o Ciclo Básico surgiu como medida democratizante em São Paulo (1984), Minas Gerais (1985), Paraná e Goiás (1988), existindo muitas semelhanças entre essa proposta nos referidos estados. Em síntese, a proposta do Ciclo Básico nesses estados, consistiu em:

- eliminar a reprovação no final do primeira série, ampliando o período de alfabetização e assegurando a continuidade deste processo;

- mudar o enfoque da avaliação, que deveria centrar-se no processo de aprendizagem, indicando o progresso do aluno e dando informações sobre as necessidades de reforço e atendimento de dificuldades específicas;

- oportunizar estudos complementares para alunos que encontrassem dificuldades para apropriação dos conteúdos;

- possibilitar a capacitação dos professores que atuavam na proposta;

- alterar a concepção e a prática de alfabetização, pela incorporação de teorias mais avançadas da Psicolingüística, Sociolingüística, Lingüística, Psicologia.

Tal como as demais políticas educacionais, nem sempre o desenvolvimento de Ciclo Básico nesses estados foi estável, sendo afetado pela descontinuidade das políticas, ausência de condições para sua plena realização, obstáculos impostos pela burocracia, fragilidade nos mecanismos de avaliação de sua eficácia, etc.

O Ciclo Básico de São Paulo e o de Minas Gerais foram, em diferentes contextos, avaliados pelos respectivos órgãos responsáveis pela proposta. Além disto, o Ciclo Básico de São Paulo já foi objeto de análise em, pelo menos, cinco dissertações de mestrado e duas teses de doutorado (Ambrosetti, 1989; Nébias, 1990; Silva, 1990; Marques, 1991; Andrade, 1992; 
Bonel, 1993; Cruz, 1994) e o de Minas Gerais, de três dissertações de mestrado (Alencar, 1989; João, 1990; Barbosa, 1991).

Em São Paulo, o Ciclo Básico foi implantado a partir de 1984, atingido apenas as duas séries iniciais. Apesar da trajetória oscilante e de um desenvolvimento desigual, as mudanças colocadas pelo Ciclo Básico resultaram numa melhoria de $10 \%$ nos índices de promoção. A partir de 1988, foi instituída a jornada única de trabalho docente e discente, aumentando a permanência de diária para seis horas-aula para os alunos do Ciclo Básico, oferecendo melhores condições de trabalho. Algumas conclusões podem ser retiradas dos estudos que avaliaram o Ciclo Básico em São Paulo. Nébias (1990) conclui que o Ciclo Básico, representou um avanço na democratização do ensino, ainda que esse avanço tenha ficado aquém das expectativas das entidades de classe, dos profissionais da rede, do nível de qualidade de ensino que os alunos têm direito e aquém do que o estado deveria ter conseguido. Para Bonel (1993), o Ciclo Básico, ao contrário de promover a integração, propiciou a segmentação, inclusive da avaliação dos alunos, havendo ausência da prática de avaliação. Além disso, observou-se uma maior permanência dos alunos na rede, embora não tenha alcançado plenamente seus propósitos.

Em Minas Gerais, o Ciclo Básico foi implantado a partir de 1985, seguindo processo similar ao adotado em São Paulo. Em 1987, a Secretaria de Educação lançou um documento intitulado Síntese Inicial do Relatório de Avaliação do CBA e Proposta de Encaminhamento, destacando que, apesar das inúmeras ações desencadeadas em 1985-1986, as escolas ainda não haviam entendido o significado social e pedagógico do trabalho de alfabetização proposto. A nova avaliação, realizada em 1989, abrangendo os quatro anos do Ciclo Básico, apontou que a Secretaria de Educação, a despeito de reconhecer a grande defasagem existente entre a proposta inicial e sua operacionalização, julgava benéfica a sua continuidade. Antes da implantação do CBA, a taxa de reprovação em Minas Gerais (1 1 a série) era da ordem de $50 \%$, baixando para cerca de $20 \%$ após o CBA; na $2^{2}$ série, a repetência era de cerca de $3 \%$, subindo para a faixa de $40 \%$ a $45 \%$ após a implantação (Silva, Davis, 1993, p. 21). Percebe- se ganhos em relação aos índices da $1 \underline{a}$ etapa, mas também o fenômeno do "adiamento da reprovação" do final da 1 a série para o final do CBA. Alencar (1989), analisando a avaliação do CBA, realizada pela Secretaria de Educação de Minas Gerais, nas escolas estaduais de 10 grau, relatada no documento: Ciclo Básico de Alfabetização: Avaliação 1985-1986, constatou que a avaliação do CBA atendeu plenamente sete dos quinze padrões de qualidade metodológica e, parcialmente, os padrões restantes. Constatou ainda que o processo de implantação, implementação e assimilação da proposta do CBA revelou-se insuficiente.

No Paraná, a implantação ocorreu em 1988 e 1989 em algumas escolas da rede estadual e de redes municipais, atingindo, a partir de 1990, a totalidade das escolas estaduais. Contou, na fase de sua implantação, com a assessoria de técnicos da Secretaria de Estado da Educação de São Paulo. As intenções do CBA, expressas nos documentos e atos oficiais eram: reverter o "fracasso escolar" nas séries iniciais; iniciar um amplo processo de reorganização da escola pública; implantar metodologias inovadoras no processo de alfabetização, incorporando avanços das diferentes áreas do conhecimento, rompendo com a concepção mecanicista e metodologias tradicionais que orientavam o processo de alfabetização; e ainda mudar o enfoque da avaliação, buscando a superação do sistema de avaliação de provas, notas e exames.

A partir de 1994, 123 escolas do Paraná implantaram o CBA de quatro anos, instituído pelo Decreto no 2.325 , de 25/5/93, que reuniu quatro séries iniciais em um único "continuum", com possibilidade de reprovação apenas no final da 4 a série. De forma progressiva, pretende-se atingir a totalidade das escolas estaduais. Esta extensão do CBA para quatro anos, no entanto, não foi precedida de uma avaliação do CBA de dois anos com relação ao impacto que gerou nos índices de aprovação, retenção e evasão; com relação à garantia das condições necessárias e previstas nos atos legais; opinião dos professores; dificuldades para sua consolidação, etc.

Analisando-se alguns dados da rede estadual - total do estado, percebe-se que a aprovação do período pós-CBA (19911992), comparada com os do período préCBA (1986-1987), diminuiu 1,1\%, a repro- 
vação elevou-se $2,4 \%$ e a evasão diminuiu $1,3 \%$. Um impacto positivo pode ser percebido comparando-se os dados da $1 \underline{a}$ série (pré-CBA) com a 1a etapa (pós-CBA): a aprovação elevou-se $31 \%$. Este impacto tem sido apontado como um aspecto positivo do Ciclo Básico pois, em tese, elimina a possibilidade de reprovação no início da escolaridade. Por outro lado, a tentativa de reunir as duas séries iniciais num "continuum" único, não se efetivou na maioria das escolas. ${ }^{1}$

Observa-se também no Ciclo Básico do Paraná outros problemas, tais como:

a) ruptura com a proposta do "continuum" de dois anos, com a "reprovação camuflada" de alunos (que retornam à etapa anterior por falta de domínio de conteúdos básicos);

b) a prática do remanejamento de alunos (recomposição de turmas), quando o CBA propõe a permanência e continuidade de professores e alunos nas etapas do Ciclo Básico. A busca da "homogeneização" das turmas revela a dificuldade no atendimento de níveis diferenciados dos alunos (heterogeneidade), associados a algumas condições, às vezes adversas, das escolas públicas (classes numerosas, número insuficiente de professores, de materiais didáticos, etc.);

c) cursos de capacitação que nem sempre atendem as necessidades concretas dos professores;

d) adoção, pelo governo estadual, de medidas antagônicas ao CBA, tais como a municipalização do ensino das séries inicias; pouca ênfase na consolidação do Currículo Básico formulado de 1988 a 1990; contratação de professores temporários; rotatividade de professores; diferenciação salarial entre professores temporários (CLT) e efetivos.

A proposta do CBA nesses três estados, tal como foi concebida/gestada, pode ser considerada coerente e positiva, porém, muitas dificuldades encontradas para o seu pleno êxito, tem sido morosamente processadas e resolvidas. No plano pedagógico, as mudanças ocorridas nesses estados constituíram-se, inegavelmente, em avanços importantes na busca/consolidação de uma prática transformadora na alfabetização.

A promoção automática, em sua versão atualizada no CBA desses estados, é complementada com referencial teórico para a prática pedagógica, com medidas auxiliares (estudos complementares para alunos que necessitam de maior tempo para apropriação de conteúdos; jornada única e hora de trabalho pedagógico - em São Paulo; renovação das propostas curriculares; capacitação de professores etc.). Estas condições atuais trazem novo sentido à promoção automática, retirando o caráter de medida isolada e pontual. Algumas dificuldades ainda permanecem: fragmentação do processo de "capacitação" de docentes, resistência dos professores à proposta, dificuldades no atendimento da heterogeneidade das classes, desempenho insuficiente de muitos alunos, fragmentada organização do trabaIho pedagógico nas escolas (ausência de trabalho coletivo e planejamento conjunto, projetos globais, intervenções sistemáticas e planejadas). Apesar dos esforços, a reprovação não foi eliminada no final do CBA ("adiamento da reprovação") e a promoção automática trouxe novas dificuldades, novas necessidades, novos desafios a serem enfrentados.

\section{Implicações e possibilidades}

É desnecessário lembrar que a reprovação é negativa em qualquer sistema de ensino. Traz repercussões negativas para os alunos (autoconceito, estímulo à evasão) e para o próprio sistema de ensino (desperdício de recursos, congestionamento do sistema). Se de um lado, entende-se que a promoção deveria ser uma qualidade inerente ao sistema; por outro, a instituição da promoção automática como medida isolada e sem a garantia de condições adequadas, gera outros problemas, talvez maiores do que aqueles para cuja solução foi empregada. Entre as implicações positivas destacam-se as seguintes:

a) cria a necessidade de se repensar o sentido da escola, das práticas avaliativas, dos conteúdos curriculares, do trabalho pedagógico e da própria organização escolar;

b) agiliza o fluxo de um maior número de alunos (principalmente quando implantadas nas quatro séries iniciais), contribuindo para a diminuição do desperdício de recursos financeiros. Pode também gerar a necessidade de expansão da ofer-

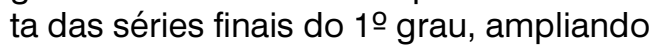

\footnotetext{
Trabalhos posteriores à elaboração deste estudo apresentam maiores dados a respeito do Ciclo Básico de Alfabetização no Paraná (Mainardes, 1995a , 1995b).
} 
as possibilidades de acesso à escolaridade obrigatória de 8 anos;

c) descongestiona o sistema, possibilitando o acesso à população escolarizável que se encontra fora da escola. Pode ocorrer, ao contrário, maior concentração de alunos nas séries nas quais é permitida a reprovação;

d) garante aos alunos maior permanência na escola, elevando assim as médias de escolaridade, em termos de anos de estudo;

e) exige a destinação de maiores recursos para a educação, a fim de garantir as condições adequadas;

f) implica mudanças na mentalidade e atitudes dos docentes;

g) implica igualmente uma mudança na mentalidade dos pais que deixariam de se preocuparem apenas com a aprovação, passando a se preocuparem também com o conhecimento que seus filhos estariam adquirindo na escola.

Entre as possíveis implicações negativas, pode-se apontar:

a) mudando um sistema que convencionalmente produz o fracasso para $100 \%$ de êxito no que se refere à reprovação, pode-se questionar se a solução não será apenas formal, diminuindo ainda mais a qualidade do ensino (principalmente pelo descompromisso evidente das políticas educacionais com a qualidade do ensino);

b) considerando-se ainda que a promoção automática pode resolver formalmente o fracasso escolar (índices de reprovação), mas não o problema real - o da aprendizagem dos alunos - pode-se questionar se a identificação tardia da fracasso da medida não prejudicará os alunos. Conjunturalmente, torna-se necessário garantir a aprendizagem efetiva dos alunos para que a promoção formal corresponda à promoção real. "Em nenhum sentido a promoção automática pode conspirar contra a qualidade da educação" (Diaz, 1987);

c) no interior das escolas poderão ser criados subterfúgios para reter alunos, ainda que a medida seja da promoção. Isto torna-se inevitável se o coletivo dos professores não concretizar, na prática escolar, as mudanças que a promoção automática requer.

\section{As possibilidades}

\section{Transformação das práticas avaliativas}

Os modelos e concepções de avaliação (formal e informal) que têm inspirado as práticas escolares podem ser considerados como aspectos que incidem sobre o fracasso escolar (reprovação, evasão e inadequação da trabalho pedagógico). Em muitas escolas ainda, as práticas avaliativas têm um sentido estreito e um caráter meramente quantitativo, baseado em provas e notas, constituindo-se um instrumento escolar autoritário, repressivo e discriminador. Este modelo de avaliação, baseado na nota, tem garantido a manutenção da "ordem institucional", da "ordem" na sala de aula, o controle do grupo e o exercício inquestionável do poder do professor.

A promoção automática impulsiona para a transformação das práticas avaliativas, assim como cria a necessidade de se rever parâmetros e critérios de promoção. Questionando a lógica vigente, a promoção automática pode fazer da avaliação um espaço de reflexão crítica e participativa sobre o desenvolvimento dos alunos, assumindo um caráter dinamizador de mudanças, pois:

- implica uma mudança no objeto de avaliação, na qual são avaliados os alunos, professores, o processo pedagógico e a própria organização institucional;

- permite que a avaliação assuma concretamente sua função diagnóstica, identificando a tempo os problemas e as dificuldades de aprendizagem dos alunos, fundamentando propostas de ação, planos de recuperação e intervenção;

- muda seu foco de atenção e utilização não somente para a promoção, mas principalmente para diagnosticar a efetividade dos métodos de ensino. Passa a ser efetivamente incorporada ao processo de ensino e aprendizagem;

- pode transformar os atuais sistemas de avaliação (baseado no quantitativo) num sistema que motiva o desejo de superação, o entusiasmo pelo saber, a alegria de estudar e aprender. Zafra (1987, p. 46), referindo-se ao processo de promoção automática implantado na Colômbia em 1987, diz que "O novo sistema de avaliação deve ori- 
entar-se na busca de uma nova consciência sobre a atividade do estudante, do educador, do pai de família baseada na responsabilidade e na participação coordenada para gerar uma nova atitude em busca das necessidades da comunidade";

- permite a criação de novos meios e procedimentos para a comunicação dos resultados aos pais e alunos e de registro do processo de aquisição do conhecimento.

\section{Transformação das concepções e práticas escolares}

A promoção automática pode propulsionar mudanças qualitativas na educação, uma vez que questiona e exige transformações radicais na escola, sua organização de tempo e espaço, programas e atividades, relações com o poder e com o saber. Esta medida:

- implica o despojamento de costumes e práticas já arraigadas no trabalho docente. Ao fazer "explícita opção pelos alunos" expressa manifesta confiança no potencial dos mesmos e possibilidades dos professores na promoção do desenvolvimento de seus alunos;

- valoriza o aluno como centro (seu ritmo, seu potencial) e a aquisição do conhecimento como finalidade principal da escola;

- elimina da cultura escolar a idéia do fracasso do aluno, uma vez que todos serão promovidos e o trabalho pedagógico deve garantir a domínio do conhecimento;

- pode influenciar transformações das relações professor/aluno(s) de autoritárias e verticais, centradas no desempenho docente - em relações horizontais, dialógicas, baseadas no reconhecimento pessoal;

- suscita mudanças que dêem novas dimensões à função social, política e cultural da escola, fazendo das práticas pedagógicas um novo espaço de relações socioculturais.

Portanto, é a prática pedagógica, baseada na consciência do professor, na vontade de transformar e na decisão coletiva, que poderá demonstrar que a medida serve para provocar as mudanças qualitativas há tanto esperadas. A competência docente, conforme demonstra Cardoso (1991) pode ser gestada através da organização do trabalho escolar, onde os professores não atuem isoladamente.
0 professor: elemento central para 0 êxito da promoção automática

Qualquer mudança educativa não se consolida apenas através de atos legais. As leis, por elas mesmas, não mudam a realidade nem transformam as instituições. As políticas decretadas, decididas de forma vertical, sem prévia e ampla discussão com os agentes que as dinamizarão no cotidiano da escola, dificilmente conseguem efetivar-se. A instituição da promoção automática, ainda que apenas nas duas séries iniciais do 10 grau, requer um intenso trabalho de formação contínua do magistério que seja menos dogmático e impositivo, sem o caráter fechado e acabado que tem caracterizado o processo de capacitação docente, mas gerando reflexões e questionamentos sobre o trabalho pedagógico e as práticas avaliativas. É possível que, colocados frente a um processo de discussão e apropriação reflexiva das mudanças propostas, os professores manifestem menor rejeição à promoção automática e mudem de atitude. Isso, porém, poderá ocorrer somente com a mudança das estratégias de capaci-tação.

Por outro lado, o magistério pode aproveitar a promoção automática para questionar o fracasso escolar, a eficiência do sistema, os conteúdos curriculares, o sentido da escola, o papel do professor e sua formação, as práticas avaliativas tradicionais e ensaiar outras formas de avaliação, alternativas para o trabalho pedagógico e exigir o cumprimento de reivindicações (históricas) do movimento docente e necessárias para a educação.

A operacionalização desta medida não é tarefa fácil, uma vez que coloca em questão costumes tradicionais, normas disciplinares e concepções de trabalho pedagógico bastante arraigadas. A desseriação, ou organização por ciclos, requer novas iniciativas, busca de novos procedimentos pedagógicos e superação de velhos esquemas.

A promoção automática vem também ampliar a heterogeneidade nas classes, o que implica na implementação de modelos distintos de ação e planejamento de estratégias didáticas que atendam aos diferentes níveis dentro da classe. Ainda que a concepção de interações sociais na sala de aula aponte para o potencial das diferentes estratégias de pensamento e ação 
dos alunos, a sua incorporação à prática pedagógica é ainda lenta e reduzida. Torna-se necessário investir na investigação e formação contínua de professores para essa nova realidade.

\section{Condições necessárias}

A instituição da promoção automática demanda uma série de condições, a fim de que não se torne uma medida apenas formal:

a) exigências de ordem estrutural: materiais didáticos diversificados, ampliação da rede física, maior permanência de alunos na escola, número menor de alunos nas salas de aula, medidas que oportunizem acompanhamento de alunos que necessitam de maior tempo para apropriação dos conteúdos, uso produtivo do tempo escolar, valorização dos profissionais da educação (incluindo melhores salários), financiamento de pesquisas, consistentes projetos de formação contínua;

b) exigências de compreensão: torna-se necessário o aprofundamento da compreensão de uma série de conceitos e práticas (práticas avaliativas, trabalho pedagógico, conteúdos curriculares);

c) compromisso efetivo do governo em garantir as condições necessárias, realizar avaliações permanentes, sensibilizar os diversos escalões para as mudanças do sistema, bem como garantir espaço de relações mais democráticas em todos os níveis dos órgãos educacionais e no processo de formação contínua.

\section{Conclusões}

A promoção automática é uma polêmica internacional. Na América Latina,

\section{Referências bibliográficas} Universidade Católica de São Paulo. apesar de sua implantação em diversos países (Panamá, El Salvador, Venezuela, Equador, Costa Rica, Colômbia, Chile, Brasil), percebe-se restrito conhecimento acumulado sobre essa modalidade, assim como a sua implantação não foi ainda suficientemente avaliada. Os estudos e pesquisas sobre a promoção automática na América Latina consideram que sua implantação sem garantia de condições necessárias, não resolve o problema, mas apenas $O$ adia.

O que parece evidente, a partir da revisão de alguns estudos e das experiências brasileiras é que o problema da reprovação e do fracasso da escola não pode reduzir-se a medidas administrativas relacionadas com o sistema de promoção, como assinala Haddad (apud Rojas Rubio, 1992, p. 77) "promover ou não promover não é o problema. O verdadeiro problema é como melhorar o nível dos alunos de baixo aproveitamento e em última instância como evitar a reprovação".

Para atingir êxito, a promoção automática não pode ser um elemento isolado e pontual, mas integrar um projeto educacional mais amplo e consistente, com a definição de conteúdos curriculares, garantia de condições básicas a todas as escolas, consistentes estratégias de formação contínua, valorização dos profissionais da educação, democratização em todos os níveis do sistema educacional, capazes de afetar a escola em seu conjunto, de modo especial, no que se refere às estratégias de ensino e práticas de avaliação e promoção. Se favorável é a tese, complexa é a sua aplicação prática. Com ou sem estratégias de promoção automática, ainda sente-se a ausência de um projeto pedagógico, que pensado a longo prazo, seja adequado às condições que reclama a educação dos setores populares.

ALENCAR, Rita Maria de Mello. Análise da avaliação do ciclo básico de alfabetização das escolas estaduais de $1^{\circ}$ grau de Minas Gerais. Rio de Janeiro, 1989. Dissertação (Mestrado) - Universidade Federal do Rio de Janeiro.

ALMEIDA JÚNIOR, A. Repetência ou promoção automática? Revista Brasileira de Estudos Pedagógicos, Rio de Janeiro, v. 27, n. 65, p. 3-15, jan./mar. 1957.

AMBROSETTI, Neusa B. Ciclo básico : o professor da escola paulista frente a uma proposta de mudança. São Paulo, 1989. Dissertação (Mestrado) - Pontifícia 
ANDRADE, Irene Rodrigues de. Ciclo básico : da proposta transformadora de alfabetização à realidade de sua prática. Campinas, 1992. Dissertação (Mestrado) - Faculdade de Educação, Universidade Estadual de Campinas.

ARELARO, Lisete Regina Gomes. Ampliação do período de alfabetização na séries iniciais : o ciclo básico em São Paulo : algumas considerações. Idéias, São Paulo, n. 1, p. 53-55, 1992.

. A ex(tensão) do ensino básico no Brasil : o avesso de um direito democrático. São Paulo, 1988. Tese (Doutorado) - Universidade de São Paulo.

AURAS, Marli. Considerações sobre a participação popular na elaboração do Plano Estadual de Educação/Santa Catarina (1985/1988) e a resposta do aparelho governamental a esse plano. Cadernos do CED, Florianópolis, v. 5, n. 2, p. 159189, jul./dez. 1988.

BARBOSA, Elisa de Oliveira. O ciclo básico de alfabetização em Minas Gerais : o risco da fogueira. Belo Horizonte, 1991. Dissertação (Mestrado) - Universidade Federal de Minas Gerais.

BONEL, Mônica Maia. O ciclo básico : um estudo de caso de uma política pública no Estado de São Paulo. Campinas, 1993. Dissertação (Mestrado) - Universidade Estadual de Campinas.

BRASIL. Ministério da Educação e do Desporto. Plano Decenal de Educação para Todos. Brasília : MEC, 1994.

CARDOSO, Terezinha Maria. O potencial educativo da organização do trabalho escolar na formação do professor das séries iniciais do primeiro grau. Belo Horizonte, 1991. Dissertação (Mestrado) - Faculdade de Educação, Universidade Federal de Minas Gerais.

CRUZ, Silvia Helena Vieira. O ciclo básico construído pela escola. São Paulo, 1994. Tese (Doutorado) - Universidade de São Paulo.

DA TEMERIDADE à mistificação. O Globo, Rio de Janeiro, 5 fev. 1993. Opinião.

DIAZ L., Carlos. Promoción con calidad. Educación y cultura, Bogotá, n. 13, p. 33-35, dic. 1987.

DURAN, Maria Claret G. O desafio de construir uma alfabetização de melhor qualidade: a proposta do ciclo básico em São Paulo. Tecnologia Educacional, Rio de Janeiro, v. 19, n. 95/96, p. 19-24, jul./out. 1990.

DUTRA, Alzira $\mathrm{H}$. et al. O avanço progressivo : uma proposta de avaliação do rendimento escolar distintiva da reorganização do ensino em Santa Catarina. Cadernos do CED, Florianópolis, v. 1, n. 1/2, p. 10-110, 1984.

EDUCACIÓN Y CULTURA. Revista del Centro del estudios y investigaciones docentes de la Federación Colombiana de educadores. (Promoción automatica). Bogotá, n. 13, dic. 1987.

FLETCHER, P., RIBEIRO, Sérgio Costa. O ensino de 1ำ grau no Brasil hoje. Em aberto, Brasília, v. 6, n. 33, jan./mar. 1987.

JOÃO, Maria Helena Soares. O ciclo básico de alfabetização em Belo Horizonte : a intenção e a realidade. Rio de Janeiro, 1990. Dissertação (Mestrado) - Universidade Federal do Rio de Janeiro.

LEITE, Dante Moreira. Promoção automática e adequação do currículo ao desenvolvimento do aluno. Pesquisa e planejamento, São Paulo, v. 3, p. 15-34, jul. 1959.

MAINARDES, Jefferson. Ciclo básico de alfabetização : da intenção à realidade. Campinas, 1995a. Dissertação (Mestrado) - Faculdade de Educação, Universidade Estadual de Campinas.

Ciclo básico de alfabetização : da intenção à realidade. Trajetos, Campinas, v. 2, n. 7, p. 39-51, dez. 1995b. 
MARQUES, Waldemar. O ensino público estadual na grande São Paulo : o ciclo básico em questão. Campinas, 1991. Dissertação (Mestrado) - Universidade Estadual de Campinas.

MUÑOZ, C., LAVIN, S. Estrategias para mejorar el acceso a la educación primaria y la permanencia en la misma. In: MUÑOZ, C. Calidad, equidad y eficiencia de la educación primaria. Santiago, Chile : CIDE, 1988.

NÉBIAS, Cleide. O ciclo básico e a democratização do ensino : do discurso proclamado às representações. São Paulo, 1990. Tese (Doutorado) - Universidade de São Paulo.

PARANÁ. Secretaria de Estado da Educação. Programa Estratégico : expansão e qualidade do ensino de 1ㅇ grau no Estado do Paraná - diagnóstico educacional. Curitiba : SEED, 1992.

RIBEIRO, Sérgio Costa. A educação e a inserção do Brasil na modernidade. Cadernos de Pesquisa, São Paulo, n. 84, p. 63-82, fev. 1993.

ROJAS RUBIO, Manuel V. Promoción automatica y fracaso escolar en Colombia. Revista Colombiana de Educación, Bogotá, n. 25, p. 73-95, 1992.

SENA, Guiomar O. de, MEDEIROS, Nina Rosa L. O sistema progressivo e suas conseqüências no Estado de Santa Catarina. Cadernos do CED, Florianópolis, v. 1. n. 1/2, p. 111-174, 1984.

SHIEFELBEIM, E., SIMMONS, J. Los determinantes del rendimiento escolar : reseña de la investigación en los países del Tercer Mundo. IDRC, 1978.

SILVA, Rose Neubauer da, DAVIS, Cláudia. É proibido repetir. Estudos em avaliação educacional, São Paulo, n. 7, p. 5-44, jan./jul. 1993.

SILVA, Zoraide Inês Faustiononi da. Ciclo básico de alfabetização nas escolas estaduais da cidade de São Paulo : um estudo em quatro escolas. São Paulo, 1990. Dissertação (Mestrado) - Pontifícia Universidade de São Paulo.

TEDESCO, Juan C. Modelo pedagógico y fracaso escolar. Revista de la CEPAL, Santiago, 1981.

ZAFRA, David C. Promoción automática en primária : mejoramiento de la calidad... o de inversión? Educación y Cultura, Bogotá, n. 13, p. 45-47, dic. 1987.

Recebido em 25 de junho de 1998.

Jefferson Mainardes, mestre em Educação pela Universidade Estadual de Campinas (Unicamp), é professor assistente do Departamento de Educação, da Universidade Estadual de Ponta Grossa (UEPG/PR). Além da docência em cursos de graduação e pós-graduação (lato sensu), desenvolve projeto de extensão universitária na área da leitura na escola.

\section{Abstract}

It has been analysed automatic promotion in Brazil, with the following basis: a) different ideas analysed in published woks and b) first experiences and actual Basic Cycle of Alphabetize (the first years of a child's Elementary School Literacy). It has been showed possibilities, implication and necessary conditions to the achievement of this proposal in the Brazilian educational system.

Key-Words: automatic promotion; basic cycle of alphabetize; educational policy. 